The following table shows the characteristics of each patient.

Conclusion HS is a rare life-threatening manifestation $(<0.5 \%)$. It must be suspected in patients with persistent fever who do not respond to antibiotics, cytopenias and evidence of multiorgan involvement.

\section{PS8:152 TRENDS AND OUTCOMES OF VENOUS THROMBOEMBOLISM IN HOSPITALISED PATIENTS WITH SYSTEMIC LUPUS ERYTHEMATOSUS: RESULTS FROM NATIONWIDE INPATIENT SAMPLE DATABASE 2003-2011}

${ }^{1} \mathrm{~S}$ Kishore, ${ }^{2} \mathrm{~V}$ Mittal, ${ }^{3} \mathrm{~T}$ Nisar, ${ }^{3} \mathrm{~S}$ Lirette, ${ }^{1} \mathrm{~V}$ Majithia. ${ }^{1}$ University of Mississippi, Division of Rheumatology, Jackson, USA; ${ }^{2}$ University of Mississippi, Division of Hospital Medicine, Jackson, USA; ${ }^{3}$ University of Mississippi, Department of Data Science, Jackson, USA

\subsection{6/lupus-2018-abstract.195}

Background/purpose Venous thromboembolism (VTE) is a major cause of morbidity and mortality in hospitalised patients particularly patients with autoimmune disorders. Nationwide Inpatient Sample (NIS) database was analysed to determine trends in rate of hospitalisation and mortality from VTE in hospitalised systemic lupus erythematosus (SLE) patients to assess its impact.

Methods 2003-2011 NIS database of Healthcare Cost and Utilisation Project was queried to identify all adults (age $>18$ years) hospitalised with SLE and VTE. Demographic characteristics and in-hospital outcomes of this population were compared to SLE patients without a VTE diagnosis. Multivariate logistic regression analysis was used to obtain adjusted odds ratio (OR).

Results The total number of hospitalised patients with SLE was 299595 of which 9175 (3.06\%) had VTE. Mean age of the study population was 50 years and $89 \%$ were females. Mean age of SLE patients with VTE was lower than those without VTE (48 vs 51 years). Rate of VTE was higher in African Americans as compared to Caucasians (3.8\% vs 2.8\%) and in males when compared to females (4.3\% vs $2.9 \%)$.

After adjusting for potential confounders, compared to those without VTE, SLE patients with VTE had higher inpatient mortality (5\% vs $2.0 \%$, OR 2.35 (CI: 2.10 to $2.62, \mathrm{p}<0.001$ ), greater disability at discharge (34\% vs $26 \%$, OR 1.53 (CI: 1.46 to 1.62 ), $\mathrm{p}<0.001$ ), longer length of stay by 3.57 days and higher cost of hospitalisation by $\$ 24500$ (table 1 ).

The rate of VTE among SLE patients have increased since 2005 as shown in Graph 1.

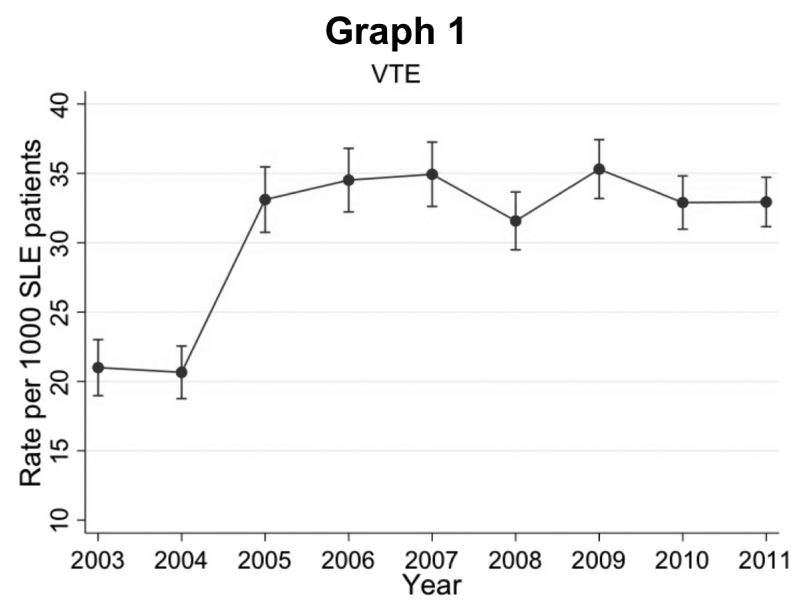

Abstract PS8:152 Figure 1

Conclusion VTE in hospitalised patients with SLE is associated with significantly higher inpatient mortality, greater disability at discharge, increased length of stay and higher cost of hospitalisation. The rate of VTE in SLE patients is on rise likely due to awareness and higher reporting. In this database patients with SLE and VTE were younger. Male sex and African-American race may be associated with an increased risk of VTE in patients with SLE. This cross-sectional study would help in the development and implementation of appropriate prophylactic strategies in high risk SLE population.

\section{PS8:153 SUBTYPES AND LOCATION OF MYOCARDIAL INFARCTIONS IN SYSTEMIC LUPUS ERYTHEMATOSUS}

I Samuelsson, I Parodis, C Anan. Karolinska Institutet, Department of Medicine, Rheumatology Unit, Karolinska University Hospital, Solna, Sweden

\subsection{6/lupus-2018-abstract.196}

Introduction Patients with systemic lupus erythematosus (SLE) are affected by morbidity and premature mortality from

Abstract PS8:152 Table 1 Outcomes

\begin{tabular}{|c|c|c|c|c|c|}
\hline Variable & All Patients & VTE & No VTE & OR & p-Value \\
\hline Inpatient Mortality & $6132(2 \%)$ & $429(5 \%)$ & $5703(2 \%)$ & $2.35(\mathrm{Cl} 2.10-2.62)$ & $<0.001$ \\
\hline $\begin{array}{l}\text { Moderate to severe } \\
\text { disability at discharge }\end{array}$ & $77904(26 \%)$ & $3117(34 \%)$ & $74787(26 \%)$ & $1.53(\mathrm{Cl} 1.46-1.62)$ & $<0.001$ \\
\hline Variable & All Patients & VTE & No VTE & Co-efficient & p-Value \\
\hline LOS Median (IQR), Days & 4 & 6 & 4 & 3.57 (Cl $3.32-3.83)$ & $<0.001$ \\
\hline $\begin{array}{l}\text { Total Charges }(\$ 10,000) \\
\text { Median (IQR) }\end{array}$ & 23100 & 36100 & 22800 & $2.54(\mathrm{Cl} 2.30-2.79)$ & $<0.001$ \\
\hline \multicolumn{6}{|c|}{ Data are presented as Number of patients $(\%)$ or Median ( \pm IQR). } \\
\hline \multicolumn{6}{|c|}{$\begin{array}{l}\text { Abbreviations: OR = Odds Ratio }(95 \% \text { Confidence Intervals }(\mathrm{CI}) \text { ); LOS = Length of stay; VTE = } \\
\text { Venous Thromboembolism; IQR = Interquartile range }\end{array}$} \\
\hline
\end{tabular}


cardiovascular disease (CVD) - commonly defined as myocardial infarction (MI), coronary artery disease (CAD), stroke and/or peripheral arterial disease (PAD). To date, neither MI subtypes, locations nor risk factors for MI specifically have been fully investigated in SLE.

Aims To study the subtypes, locations and risk factors of the first-time MI in patients with SLE.

Material and methods SLE patients with a first-time MI (SLEMI), meeting the Third Universal Definition of MI, were included in a cross-sectional investigation of our SLE cohort $(n=650)$. As comparators, MI-free SLE patients (SLE-nonMI) from the same cohort were individually matched for age and gender. Data were collected through retrospective medical record review, including reports on ECG, echocardiography and coronary angiography. Potential risk factors for MI were investigated; previous CVD, including $\mathrm{CAD}$ (comprising stable $\mathrm{CAD}$ and unstable angina), ischaemic stroke and PAD, venous thromboembolism, diabetes, smoking habits, anti-phospholipid syndrome (APS), lupus nephritis, estimated glomerular filtration rate, prednisone equivalent dosage at MI, plasma/serum albumin, CRP and erythrocyte sedimentation rate. Paired tests, McNemar's and Wilcoxon's signed rank tests, were used as appropriate.

Results MI was diagnosed in 43/650 patients, 41/43 had a non-iatrogenic MI - i.e. MI not related to percutaneous coronary intervention, stent thrombosis or coronary artery bypass grafting. Of these, non-ST-elevation MI (NSTEMI) and MI with significant coronary atherosclerosis were the most prevalent subtypes (69\% and 89\%, respectively). Furthermore, atherosclerosis in the left anterior descending artery (LAD) was present in $75 \%$ of patients. The following factors differed between SLE-MI and SLE-nonMI: CVD (43\% versus 20\%; $\mathrm{p}=0.03)$, CAD $(30 \%$ versus $0 \% ; \mathrm{p}=0.0002)$, diabetes $(15 \%$ versus $0 \% ; \mathrm{p}=0.001)$, and albumin levels (35 g/L versus $40 \mathrm{~g} /$
L; $p=0.0004) .23 \%$ of SLE-MI and $10 \%$ of SLE-nonMI patients met the criteria for definite APS prior to MI $(\mathrm{p}=0.17)$; post-MI, APS prevalence increased in patients with SLE-MI (43\% versus 10\%; $\mathrm{p}=0.0009)$.

Conclusions NSTEMI with angiography-verified atherosclerosis, most commonly in LAD, was the most prevalent MI subtype. Previous CVD (especially CAD), APS, diabetes, and decreased albumin levels distinguished SLE patients with MI from SLE patients without MI.

\section{PS8:154 THERAPEUTIC AND CARDIOVASCULAR DISEASE BURDEN IN UNDIFFERENTIATED CONNECTIVE TISSUE DISEASE AND SYSTEMIC LUPUS ERYTHEMATOSUS: RESULTS FROM THE LUPUS EXTENDED AUTOIMMUNE PHENOTYPE STUDY (LEAP) COHORT}

'S Dyball, 1,2J Reynolds, 1,2IN Bruce, 1,2B Parker. 'Arthritis Research UK Centre for Epidemiology, Centre for Musculoskeletal Research, Institute of Inflammation and Repair, Manchester, UK; ${ }^{2}$ NIHR Manchester Musculoskeletal Biomedical Research Unit, Central Manchester University Hospital NHS Foundation Trust, Manchester, UK

\subsection{6/lupus-2018-abstract.197}

Purpose Connective tissue diseases (CTDs) are heterogeneous with overlapping clinical features and shared immunopathology. We sought to assess clinical characteristics, arterial stiffness and therapeutic exposures in a mixed CTD cohort using both clinician diagnosis and classification criteria. We specifically compared these factors in undifferentiated CTD (UCTD) and systemic lupus erythematosus (SLE).

Method Data was collected prospectively in 181 CTD patients in Lupus Extended Autoimmune Phenotype Study (LEAP) between May-2014 and June-2017. Patients were

Abstract PS8:154 Table 1 Baseline characteristics and clinical variables in all patients, and according to clinician diagnosis

\begin{tabular}{|c|c|c|c|c|c|c|c|c|c|}
\hline Variable & $\mathbf{N}$ & $\begin{array}{l}\text { All } \\
\text { patients } \\
\mathrm{N}=181\end{array}$ & $\begin{array}{l}\text { UCTD } \\
\mathrm{N}=49\end{array}$ & $\begin{array}{l}\text { SLE } \\
\mathrm{N}=73\end{array}$ & $\begin{array}{l}\text { Siögren's } \\
\text { syndrome } \\
\mathrm{N}=24\end{array}$ & $\begin{array}{l}\text { Scleroderma } \\
\mathrm{N}=15\end{array}$ & $\begin{array}{l}\text { Myositis } \\
\mathrm{N}=9\end{array}$ & $\begin{array}{l}\text { MCTD } \\
\mathrm{N}=11\end{array}$ & $\begin{array}{l}\mathrm{p}- \\
\text { value }\end{array}$ \\
\hline \multicolumn{10}{|l|}{ Baseline characteristics } \\
\hline $\begin{array}{l}\text { Age in years, median } \\
\text { (IQR) }\end{array}$ & 180 & $\begin{array}{l}48(36, \\
57)\end{array}$ & $\begin{array}{l}45(33, \\
52)\end{array}$ & $44(33,54)$ & $\begin{array}{l}52.5(42, \\
58)\end{array}$ & $60(57,68)$ & $\begin{array}{l}54(51, \\
57)\end{array}$ & $\begin{array}{l}47(37, \\
51)\end{array}$ & $<0.001$ \\
\hline Female, $\mathbf{N}(\%)$ & 181 & $169(93.4)$ & 45 (91.8) & $71(97.3)$ & $22(91.7)$ & $15(100)$ & $9(100)$ & $7(63.6)$ & 0.002 \\
\hline $\begin{array}{l}\text { Disease duration (years), } \\
\text { median (IQR) }\end{array}$ & 172 & $6(3,15)$ & $3.5(1,7)$ & $11(5,16)$ & $5(2,15)$ & $7(3,16)$ & $3(1,4)$ & $5(3,7)$ & 0.0001 \\
\hline Anti-malarial use, $N(\%)$ & 176 & $127(72.2)$ & $35(74)$ & $65(92)$ & $12(50)$ & $3(20)$ & $5(62.5)$ & $7(63.6)$ & $<0.001$ \\
\hline Oral steroid use, $\mathrm{N}(\%)$ & 179 & $116(64.8)$ & $20(44)$ & $62(90)$ & $7(29)$ & $6(43)$ & $7(87.5)$ & $7(63.6)$ & $<0.001$ \\
\hline Biologic use, $\mathrm{N}(\%)$ & 173 & $14(8.1)$ & $1(2)$ & $11(16)$ & $1(4)$ & $1(7)$ & $0(0)$ & $0(0)$ & 0.071 \\
\hline $\begin{array}{l}\text { Immunosuppressant use, } \\
\mathrm{N}(\%)\end{array}$ & 167 & $84(50.3)$ & $15(33)$ & $46(69)$ & $7(29)$ & $3(23)$ & $5(62.5)$ & $8(80)$ & $<0.001$ \\
\hline Smoking, N(\%) & 181 & $80(44.2)$ & $23(46.9)$ & $33(45.2)$ & $8(33.3)$ & $8(53.3)$ & $5(55.6)$ & $3(27.3)$ & 0.611 \\
\hline $\begin{array}{l}\text { Systolic BP (mmHg), } \\
\text { median (IQR) }\end{array}$ & 162 & $\begin{array}{l}124(115 \\
138)\end{array}$ & $\begin{array}{l}131(115, \\
132)\end{array}$ & $\begin{array}{l}123(115, \\
132)\end{array}$ & $\begin{array}{l}122(114, \\
141)\end{array}$ & $\begin{array}{l}133(117, \\
142)\end{array}$ & $\begin{array}{l}142(126, \\
158)\end{array}$ & $\begin{array}{l}123(111, \\
135)\end{array}$ & 0.1743 \\
\hline $\begin{array}{l}\text { Cholesterol (mmol/L), } \\
\text { median (IQR) }\end{array}$ & 132 & $\begin{array}{l}4.6(3.9, \\
5.2)\end{array}$ & $\begin{array}{l}4.6(3.9, \\
5.3)\end{array}$ & $4.5(3.9,5)$ & $\begin{array}{l}4.7(3.9, \\
5.2)\end{array}$ & $4.9(4.1,5.6)$ & $\begin{array}{l}5.5(4.9 \\
6.4)\end{array}$ & $\begin{array}{l}4.8(3.7, \\
5.3)\end{array}$ & 0.4148 \\
\hline \multicolumn{10}{|c|}{ Cardiovascular manifestations } \\
\hline Serositis, N (\%) & 142 & $26(18)$ & $4(10)$ & $19(31)$ & $1(6)$ & $2(25)$ & $0(0)$ & $0(0)$ & 0.019 \\
\hline $\begin{array}{l}\text { Pulmonary artery } \\
\text { hypertension, } \mathrm{N}(\%)\end{array}$ & 179 & $3(2)$ & $0(0)$ & $1(1)$ & $0(0)$ & $2(13)$ & $0(0)$ & $0(0)$ & 0.016 \\
\hline $\begin{array}{l}\text { Interstitial lung disease, } \mathbf{N} \\
(\%)\end{array}$ & 179 & $15(8)$ & $2(4)$ & $1(1)$ & $1(4)$ & $3(20)$ & $4(44)$ & $4(36)$ & $<0.001$ \\
\hline Pulmonary fibrosis, N (\%) & 179 & $6(3)$ & $0(0)$ & $0(0)$ & $0(0)$ & $2(13)$ & $2(22)$ & $2(18)$ & $<0.001$ \\
\hline \multicolumn{10}{|l|}{ Renal manifestations } \\
\hline Proteinuria, N (\%) & 177 & $22(12)$ & $0(0)$ & $19(27)$ & $0(0)$ & $1(7)$ & $0(0)$ & $2(18)$ & $<0.001$ \\
\hline Nephrotic, N (\%) & 132 & $6(5)$ & $0(0)$ & $6(11)$ & $0(0)$ & $0(0)$ & $0(0)$ & $0(0)$ & 0.117 \\
\hline Haematuria, N (\%) & 179 & $16(9)$ & $0(0)$ & $16(23)$ & $0(0)$ & $0(0)$ & $0(0)$ & $0(0)$ & $<0.001$ \\
\hline Nephritis, N (\%) & 179 & $8(4)$ & $0(0)$ & $8(11)$ & $0(0)$ & $0(0)$ & $0(0)$ & $0(0)$ & 0.026 \\
\hline Renal biopsy, $\mathbf{N}(\%)$ & 178 & $18(10)$ & $0(0)$ & $15(21)$ & $0(0)$ & $1(7)$ & $0(0)$ & $2(18)$ & 0.002 \\
\hline \multicolumn{10}{|l|}{ Arterial stiffness } \\
\hline PWV (m/s), median (IQR) & 159 & $\begin{array}{l}7.8(6.7, \\
9.7)\end{array}$ & $\begin{array}{l}7.65 \\
(6.7,9.8)\end{array}$ & $\begin{array}{l}7.45(6.5 \\
9.4)\end{array}$ & $\begin{array}{l}8.1(5.7, \\
9.7)\end{array}$ & $10(8.4,11.1)$ & $\begin{array}{l}9.5(7.6, \\
9.8)\end{array}$ & $\begin{array}{l}7.9(6.1, \\
8.9)\end{array}$ & 0.0946 \\
\hline
\end{tabular}


initially grouped according to clinician diagnosis. Patients with a clinician diagnosis of UCTD were reviewed and reclassified, where appropriate, using ACR-1982/1997 SLE, ACR/EULAR-2016 Sjögren's syndrome, ACR/EULAR-2013 Systemic Sclerosis, and 1975-Myositis criteria. Arterial stiffness (pulse wave velocity-PWV) was measured using the TensioMed device (TensoMed-LTD, Budapest). PWV between groups was analysed by linear regression, and adjusted for confounders (age, gender, ethnicity, smoking, systolic blood pressure and disease duration).

Results Baseline characteristics are described in Table-1. UCTD patients had comparatively shorter disease duration than many CTDs but significant treatment burden with 15 (33\%) taking an immunosuppressant and 20 (44\%) taking oral-steroids. UCTD patients had no renal disease and lower serositis compared to the SLE cohort. As expected, pulmonary artery hypertension and interstitial lung disease were comparatively lower in UCTD. Using classification criteria, 15 UCTD patients could be reclassified as SLE and 1 as Sjögren's syndrome; relating predominately to musculoskeletal and cutaneous features including ulcers-(30.6\%), photosensitive rash(40.8\%) and arthritis-(55.1\%) rather than deep-organ manifestations. There was higher immunosuppressant-use in reclassified UCTD patients (62\% vs $39 \%, \mathrm{p}=0.013)$ suggesting they required more aggressive intervention. The UCTD and SLE cohorts were of similar ages and had comparable PWV (7.65 vs $7.45 \mathrm{~m} / \mathrm{s}, \mathrm{p}=0.746$ ), with no significant differences even when UCTD patients were reclassified. A historic control group of 19 healthy subjects aged 30.7 years $(25.0,32.9)$ had a PWV of $6.20 \mathrm{~m} / \mathrm{s}$ suggesting UCTD patients have increased cardiovascular burden, similar to SLE.

Conclusions Patients diagnosed with UCTD may meet classification criteria for other CTDs and it is important to continuously reassess these patients for new or evolving features. UCTD patients are also often exposed to significant therapies, including immunosuppressants. There is similar arterial stiffness to the SLE cohort suggesting a comparatively high cardiovascular burden.

\section{PS8:155 THE PREVALENCE OF HEAVY MENSTRUAL BLEEDING (MENORRHAGIA) IN PATIENTS WITH SYSTEMIC LUPUS ERYTHEMATOSUS (SLE)}

${ }^{1} \mathrm{C}$ Wincup, ${ }^{2} \mathrm{~T}$ Richards, ${ }^{1} \mathrm{~A}$ Rahman. ${ }^{1}$ Department of Rheumatology, University College London, UK; ${ }^{2}$ Centre for CardioVascular and Interventional Research (CAVIAR), Division of Surgery, University College London, UK

\subsection{6/lupus-2018-abstract. 198}

Background Heavy menstrual bleeding (HMB) affects 27\% of the general female population and may ultimately result in iron deficiency and anaemia. Given that systemic lupus erythematosus (SLE) predominantly affects women of childbearing age it is important to consider the burden of $\mathrm{HMB}$ in these patients.

Purpose To identify the prevalence of HMB in pre-menopausal women with SLE.

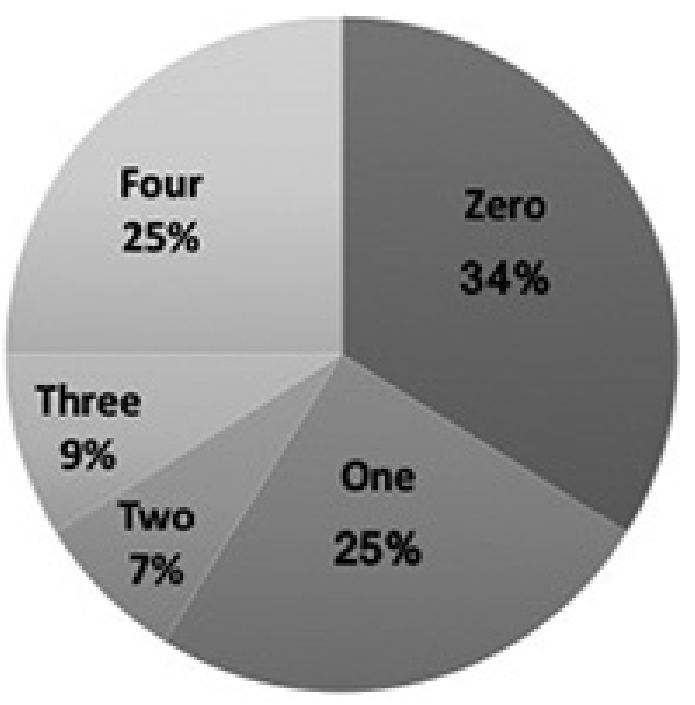

Abstract PS8:155 Figure 1 Total number of risk factors for HMB in all menstruating patients

Methods From May 2017, female patients fulfilling revised ACR criteria diagnosis of SLE were asked to complete a health questionnaire including sections on anaemia and menstrual history based upon a similar validated questionnaire that has previously been used in other previous large studies to assess for HMB prevalence. Patients were considered to have $\mathrm{HMB}$ if two or more of the following criteria were met;

- passing of large blood clots,

- need for double sanitary protection,

- need for frequent changes of tampons or towels (every 2 hours or less),

- flooding to clothes/bedding.

Patients were also asked how many menstrual periods they had in the previous 12 months and whether they had sought medical help for HMB before.

Results A total of 107 patients completed the questionnaire (Age range 17-82; median 42; IQR 32-52). For the purpose of this study we included only the 68 patients who reported having at least one menstrual period in the last 12 months (Age range 17-51; median 35; IQR 29-40). The majority (31/ $68 ; 46 \%)$ had 12 periods in the previous year and only 9/68 $(13 \%)$ had less than 6 periods in that time. Over a third (24/ $68 ; 35 \%)$ reported they had sought help for symptoms of HMB in the past. Of the 68 patients who had atlas one menstrual period in the last year; 41\% (28/68) reported two or more of the features that would fit with a diagnosis of HMB; see figure 1 . The prevalence of each of the four risk factors is summarised in figure 2.

Conclusions The prevalence of HMB in women with lupus $(41 \%)$ is higher than in previous studies of the general population $(27 \%)$ thus increasing the risk of iron deficiency. 